\title{
A IMPORTÂNCIA DA METEOROLÓGIA PARA A AGRICULTURA NO ALTO SERTÃO PARAIBANO
}

\author{
SILVA D.C ${ }^{1}$; FIGUEREDO G.M²; SILVA A.M ${ }^{3} ;$ FIGUEREDO L.F $;$;ESQUITA E.F ${ }^{5}$ \\ ${ }^{1}$ Graduanda em Licenciatura Plena em Ciências Agrárias, Universidade Estadual da Paraíba, UEPB/CCHA, Catolé do Rocha- \\ PB.dayara-silva-12@hotmail.com \\ ${ }^{2}$ Graduanda em Licenciatura Plena em Ciências Agrárias, Universidade Estadual da Paraíba, UEPB/CCHA, Catolé do Rocha- \\ PB.kekinha_36@hotmail.com \\ ${ }^{3}$ Graduada em Licenciatura Plena em Ciências Agrárias, Universidade Estadual da Paraíba, UEPB/CCHA, Catolé do Rocha- \\ PB.adanielita.maria@outlook.com \\ ${ }^{4}$ Doutoranda em Agronomia, Universidade Federal da Paraíba, UFPB/CCA, Areia-PB. lucimara.ufpb@ gmail.com \\ ${ }^{5}$ Prof. D.Sc. Universidade Estadual da Paraíba-CCHA, Catolé do Rocha-PB. elmesquita4@uepb.edu.br
}

\section{Introdução}

O manejo correto da irrigação em condições de clima semiárido tem como finalidade a promoção do uso racional da água no setor agropecuário, em especial na agricultura familiar local, por causa da redução hídrica nos últimos cinco anos, permitindo assim, maior eficiência no consumo de água e a sustentabilidade econômica, social e ambiental. A agricultura familiar local é cultivada predominantemente por sistema extensivo, sem nenhuma prática agrícola, e caracterizada pelo uso intensivo do solo, manejo inadequado da irrigação. Esses dois fatores são causas que normalmente acarretam prejuízos ao meio ambiente e aos produtores rurais. Portanto, a região de Catolé do Rocha possui também amplas áreas agrícolas disponíveis à expansão da agricultura familiar com viabilidade econômica, caso haja a adoção de inovações tecnológicas, como a técnica da irrigação que possibilita a produção com qualidade durante o período da estiagem, sem perdas comprometedoras da produção. O projeto de extensão consiste na sociabilização da evapotranspiração oriunda da estação meteorológica de Catolé do Rocha, PB, à sustentabilidade da irrigação na agricultura familiar do município, bem como uso racional da água.

\section{Relato de Experiência}

Esse relatório vai nos mostrar a respeito da estação meteorológica do campus IV da cidade de Catolé do Rocha na Paraíba, tem como principal objetivo a redução hídrica de consumo de água para a agricultura familiar, além de fornecer dados com a finalidade de melhorar a produtividade das culturas locais.com isso ajudará o produtor na economia de água e minimizarão o processo de salinização dos solos, presentes na mesorregião devido ao uso inadequado da irrigação e uso indiscriminado de fertilizantes químicos.

A pesquisa foi desenvolvida no ano de 2016 na estação meteorológica, localizada na Universidade Estadual da Paraíba, Campus IV, Catolé do Rocha-PB. A evaporação de referência $\left(\mathrm{ET}_{0}\right)$ através do tanque de Classe "A". Para cálculo da evapotranspiração de referência (ETo), pelo método do tanque de Classe $\mathrm{A}$ foi obtido pela equação: $\mathrm{ET}_{0}=$ Evaporação do tanque $\mathrm{x}$ coeficiente do tanque $(0,75)$, sendo coletado diariamente. A precipitação está sendo coletada através de um pluviômetro, instado dentro da estação. Os dados abaixo vão mostrar a precipitação pluviométrica, o nível de evaporação do tanque classe "A", o reabastecimento diário do tanque e a evaporação da estação.

Tabela 1: Dados relacionados os tanque classe "A", precipitação pluviométrica e evaporação diária. 


\begin{tabular}{ccccc}
\hline 2016 & Prec(mm) & Micr(mm) & Tanq/reab & Evap do tanq \\
\hline Média & 1,55 & 116,38 & 20,40 & 18,50 \\
Erro padrão & 0,52 & 42,63 & 1,17 & 10,52 \\
Desvio padrão & 1,79 & 147,67 & 4,05 & 36,44 \\
Variância da amostra & 3,20 & 21805,68 & 16,42 & 1328,02 \\
Mínimo & 0 & 48,926 & 14,61692308 & 5,7632 \\
Máximo & 4,88 & 528,28 & 27,70 & 134,12 \\
\hline CV(\%) & 115,30 & 126,89 & 19,86 & 197,03 \\
\hline
\end{tabular}

Tanque classe A

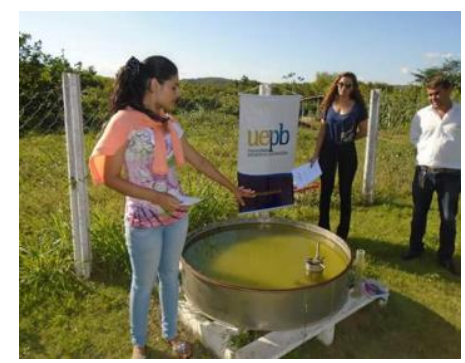

Figura 1: Tanque classe "A", onde retiramos os dados diariamente, reabastecimento e evaporação.

\section{Considerações}

$\mathrm{Na}$ estação meteorológica da cidade de catolé do Rocha teve como principal objetivo além de fornecer dados pros demais projetos do próprio campus, teve como finalidade ajudar ao produtor rural como economizar na irrigação das suas culturas, auxiliado aos mesmos a melhoria na sua produção. Ajudando ao produtor principalmente nos período secos da nossa região, ensinando aos mesmos o reaproveito da água na nivelação correta para cada cultura. Diante disso, os dados fornecidos na estação meteorológica é uma tecnologia para melhorar a produtividade das culturas locais, mas, para isto, precisa ser divulgado, bem como, uma capacitação dos produtores rurais para poderem se beneficiar desta tecnologia, essencial para condições climáticas locais. Esta ferramenta ajudará o produtor na economia de água e minimizarão o processo de salinização dos solos, presentes na mesorregião devido ao uso inadequado da irrigação e uso indiscriminado de fertilizantes químicos.

\section{Referências}

CARDOSO, G. G de G. Manejo da irrigação da alface em ambiente protegido. 2011. $86 \mathrm{f}$. Tese (Doutorado em Agronomia Irrigação e Drenagem) - Faculdade de Ciências Agronômicas Universidade Estadual Paulista Júlio de Mesquita Filho. Botucatu, 2011.

MIRANDA, M. J. de; PINTO, H. S.; ZULLO JÚNIOR, J.; FAGUNDES, R. M.; FONSECHI,D. B.; CALVE, L. PELLEGRINO, G. Q. A classificação climática de Koeppen para o estadode São Paulo. Disponível em: http://www.cpa.unicamp.br/outras-informacoes/clima-dosmunicipiospaulistas.htmlAcesso em: 18 jan. 2014.

REICHARDT, K.; TIMM, L. C. Solo, Planta e Atmosfera: Conceitos Processos e Aplicações. São Paulo: Manole, 2004. 478 p.

SANTOS, G. O.; HERNANDEZ, F. B. T.; ROSSETI, J. C. Balanço hídrico como ferramenta ao planejamento agropecuário para a região de Marinópolis, Noroeste do estado de São Paulo. Revista Brasileira de Agricultura Irrigada, Fortaleza, v.4, n.3, p. 142-149, 2010. 